\title{
Paediatric dental A\&E service during the COVID-19 pandemic
}

\author{
P. Sookaromdee ${ }^{1} \cdot$ V. Wiwanitkit ${ }^{2}$
}

Received: 4 January 2021 / Accepted: 4 March 2021 / Published online: 12 April 2021

(c) European Academy of Paediatric Dentistry 2021

\section{Dear Editor,}

We would like to share ideas on the article entitled "Paediatric dental A\&E service during the COVID-19 pandemic in the Greater London area (Patel et al. 2021)." Patel et al. (2021) concluded that "Remote telephone consultations and digital photographs were useful to screen emergency paediatric dental patients, but lack of face-to-face consultations with radiographic assessment and access to general anaesthetic services were major limiting factors." Indeed, there are many other possible problems that should be mentioned. First, the internet speed plays important role in communication. The remote setting might experience the problem of disrupted internet communication. Additionally, some practitioner might experience the technological barrier for starting telehealth communication (Imlach et al. 2020). Second, the paediatric patient might have problem in giving factual content in telephone communication. There might be incorrect data giving. Selection of cases for telephone consultation, which is an important point for a good communication (Hasani et al. 2020), might not possible for emergency case. Third, the privacy of communication is important. There must be the security system to protect patient's privacy. Last, there must be a good training for staff for using the system.

\section{Declarations}

Conflict of interest The authors declare that they have no conflict of interest.

\section{References}

Hasani SA, Ghafri TA, Al Lawati H, Mohammed J, Al Mukhainai A, Al Ajmi F, Anwar H. The use of telephone consultation in primary health care during COVID-19 pandemic, Oman: perceptions from Physicians. J Prim Care Community Health. 2020;11:2150132720976480.

Imlach F, McKinlay E, Middleton L, Kennedy J, Pledger M, Russell L, Churchward M, Cumming J, McBride-Henry K. Telehealth consultations in general practice during a pandemic lockdown: survey and interviews on patient experiences and preferences. BMC FamPract. 2020;21:269.

Patel N, Viswanathan A, Lee J, Barrow S, Cant A, Sanghvi R, Deseta M, Layton J, Bhujel N, Sheehy EC. Paediatric dental A\&E service during the COVID-19 pandemic in the Greater London area. Eur Arch Paediatr Dent. 2021. https://doi.org/10.1007/s40368-02000589-9 (Online ahead of print).

Publisher's Note Springer Nature remains neutral with regard to jurisdictional claims in published maps and institutional affiliations.
P. Sookaromdee

pathumsook@gmail.com

Bangkok, Thailand

2 Dr DY Patil University, Pune, India 